\title{
APPLICATION OF TUMOR MARKERS IN OVARIAN MALIGNANCIES
}

*T. Malati, G.Rajani Kumari and B. Yadagiri

Department of Biochemistry, Nizam's Institute of Medical Sciences, Punjagutta, Hyderabad-500082, Andhra Pradesh, India

\section{ABSTRACT}

Ovarian cancer is the fifth leading cause of death in women. The incidence of this malignancy increases in women over the age of 40 . The overall five years survival is less than $30 \%$, as most women present with advanced stage disease. Until recently, detection of early stage ovarian cancer has been difficult since it is usually nonpalpable and asymptomatic. The definitive diagnosis of an ovarian mass is a common problem in gynecologic patients with adnexal mass. The routine standard evaluation for adnexal masses includes patient's history, physical examination, ultrasound and histopathological examination. These parameters individually or in combination have little predictive value. The accuracy of diagnostic tools are of immense value and great concern to practicsing Gynecologists and Oncologists. The clinical application of serum concentration of CA 125, AFP and hCG is of great help not only as diagnostic aid but also in monitoring efficacy of any treatment modality like chemotherapy, radiotherapy or surgical resection. Additionally, evaluation of tumor marker concentration helps in predicting early biochemical recurrence and in prognostication in different types of ovarian malignancies. The ability to differentiate a malignant mass from a benign pelvic mass pretherapeutically could be enhanced optimally by additional use of tumor markers such as cancer antigen CA-125, alphafetoprotein and human chorionic gonadotrophin in pre-and postmenopausal women.

KEY WORDS : Ovarian malignancy, tumor marker, CA 125, AFP, hCG.

\section{INTRODUCTION}

Ovarian malignancy is one of the top ten leading cancers in Indian women and it accounts for nearly $25 \%$ of all gynecological malignancies in women. This cancer comprises heterogeneous spectrum of different malignant histological cell types. Among different cell types, epithelial ovarian cancer is most prevalent and lethal malignancy in the developed world (1). However, its prevalence is not uncommon in developing countries (2). The incidence of carcinoma of ovary varies in different populations of the world. For example, the average

\footnotetext{
"Author for correspondence:

Or. T. Malati, Prof. \& Head, at above address E-mail : malati@hd2.vsnl.net.in, Fax: 3310076
}

annual age adjusted incidence rates per 100,000 for different racial and ethnic groups of women residing in U.S.A. showed highest rates for Whites (14.1) and lowest for Japanese women (8.5). The varied incidences in Hawaiians (13.2), Hispanics (11.3), Chinese (10.3), Blacks (9.8), Filippinos (9.7) and American Indians (8.9) indicated some degree of genetic predisposition and/or different dietary habits. The average annual incidence rates were higher in US white women (50 per 100,000) compared to white women in Europe (15 per $100,000)$. The overall mortality rates were 8.0 per 100,000 women population in US (3). The overall five-year survival rates were highest $(82-92 \%)$ in patients with localized tumor and a rapid decline of survival rates $(51-69 \%)$ was observed in subjects

"Seth G.S. Medical College and K.E.M. Hospital Oration by Dr. T. Malati at the 27th Annual Conference of the Association of Clinical Biochemists of India at Nagpur, 11-14 January 2001. 
with locoregional spread. The survival rate among sübjects with distant metastasis was only $12-17 \%$ (4).

The World Health Organisation (WHO) and Intemational Federation of Gynecology and Obstetrics (FIGO) have broadly classified ovarian malignancies into 1) Common epithelial tumor, 2) Sex cond stromal tumors and 3) Germ cell tumors. Vast majority (85\%$90 \%$ ) of malignant ovarian tumors are of epithelial type. Fewer than $10 \%$ of all the ovarian tumors are of stromal origin. Germ cell tumors constitute less than $5 \%$ of all ovarian malignancies and are of great relevance as they occur in teen age and young women with vastly different natural history than epithelial tumors. Contrary to germ cell tumors (endodermal sinus tumor, dysgerminomas, embryonal carcinoma, choriocarcinoma), the epithelial tumors are rarely seen before menarche and their maximum incidence is observed during $6^{\text {th }}$ and $7^{\text {th }}$ decade in Western population. Patients of ovarian malignancies usually exhibit symptoms of vaginal bleeding, abdominal pain and adnexal mass on abdominal ultrasound scanning (5). Preoperative studies usually include chest $x$-ray, abdomen ultrasound and determination of serum and ascitic fluid tumor markers.

Tumor markers are biochemical substances elaborated by tumor cells either due to the cause or effect of malignant and non-malignant tumors. Extensive efforts were made in the past two decades to detect tumor specific antigens by using variety of immunological, biochemical and molecular tools. The studies on various tumor markers have contributed significantly for their role in helping diagnosis, early detection, monitoring and management of radiotherapy, surgery and chemotherapy and also in predicting prognosis (6).

Several tumor markers have been identified for variety of malignancies. However, tumor markers for primary ovarian malignancies of clinical relevance for different histological cell types are only a few as given in table 1.

The tumor markers listed in table 1 may be present normally at low level but are produced in greater amounts in cancer cells. These could also be products of genes that remained unexpressed in the normal cells. Depending on the malignant cell type, a single organ can elaborate many cancer markers. For example, Adenocarcinoma of ovary could be frequently positive for CA 125 and rarely positive for Carcinoembryonic Antigen (CEA). The endodermal sinus tumors of ovary invariably show positivity for AFP and Choriocarcinoma for hCG (7-10).

The diagnostic efficiency of tumor markers depends on variety of factors such as sensitivity, specificity, positive predictive value (PPV) and negative predictive value (NPV). The sensitivity of tumor marker is the probability that the test results will be positive if a tumor is positive. Specificity of tumor marker as a screening parameter indicates whether it may be used for describing in what percentage of healthy individuals the test result is negative. The PPV describes the probability that the disease in question is actually present if the test result is positive. Negative Predictive Value (NPV) describes the probability that the disease

Table 1. Clinically applicable tumor markers of cancer ovary.

\begin{tabular}{ll}
\hline \multicolumn{1}{c}{ Tumor Marker } & \multicolumn{1}{c}{ Type of Ovarian Malignancy } \\
\hline $\begin{array}{l}\text { Cancer Antigen CA 125 } \\
\text { (CA 125) }\end{array}$ & Marker of first choice for epithelial ovarian malignancy \\
$\begin{array}{l}\text { Human chorionic Gonadotrophin } \\
\text { (hCG) }\end{array}$ & Marker of 1st choice for Choriocarcinoma ovary \\
$\begin{array}{l}\text { Alphafetoprotein } \\
\text { (AFP) }\end{array}$ & Marker of 1st choice for endodermal sinus tumor of ovary \\
HCG and/ or AFP & Mixed germ cell tumor of ovary \\
\hline
\end{tabular}


is not actually present if the test result is negative. The study of tumor marker should be useful for early detection and diagnosis of malignamt process. It should be useful for detecting and predicting the efficacy of surgical resection and assessment of metastasis. It should also help in monitoring therapeutic effectiveness.

\section{Cancer antigen 125 (CA 125)}

CA 125 was detected by using murine monoclonal antibody OC 125 generated by immunization against histologically well defined ovarian adenocarcinoma cell line. OC 125 monoclonal antibody recognizes multiple antigenic repeating determinants on a high molecular weight (>220 Kda) glycoprotein. These epitopes are also detected in fetal coelomic epithelium, mullerian duct remnants, amnion and amniotic fluid. CA 125 antigenic determinants are not found in normal adult ovarian tissues but are associated with epithelial ovarian carcinoma (11-17).

Apparently healthy women without any ovarian mass (benign or malignant) show CA 125 levels less than $35 \mathrm{u} / \mathrm{ml}$ in their serum. Globally, this value is chosen as the cut off value, i.e. upper limit of normal range. CA 125 was proved to be marker of first choice for epithelial carcinoma of ovary. The marker shows higher sensitivity for non-mucinous epithelial ovarian carcinoma compared to mucinous epithelial ovarian carcinoma. The sensitivity of serum CA 125 for pretreatment ovarian carcinoma varied from $43 \%-97 \%$ depending on the stage of ovarian malignancy. The progressive increase of sensitivity was observed from stage I to stage IV (stage $1: 43 \%$, stage II: $85 \%$, stage III: $93 \%$, stage IV: $97 \%$, overall sensitivity for all stages : $82 \%$ ) thus reflecting that the sensitivity increases with advancing stage of malignancy (18-22). In addition, this marker is also reported to be elevated in malignancies of breast $(17.6 \%)$, colorectal (15.1\%), gastric $(30.9 \%)$, esophagus $(10.5 \%)$, liver $(49 \%)$, biliary tract $(45.8 \%)$, pancreas $(52.6 \%)$, lung $(29.5 \%)$, and endometrium (31.8\%). An increase of more than $35 \mathrm{u} / \mathrm{ml} \mathrm{CA} 125$ was also reported in almost $10.4 \%$ of benign ovarian tumors (23-26).
We have undertaken with the aims and objectives to study in depth the role of 1) CA 125 , in healthy women, in women with benign and malignant disease and 2) to assess clinical applications of CA 125, AFP and hCG as diagnostic aid in monitoring efficacy of different treatment modalities in predicting tumor regression, progression, and in prognostication.

\section{MATERIALS AND METHODS}

Serum AFP and hCG were measured by employing double monoclonal antibody sandwich enzyme linked immunoabsorbent assay. The enzymun-test CA $1252^{\text {nd }}$ generation tumor marker assay was employed using $M 11$ and $O C 125$ monoclonal antibodies. In this assay, biotinylated antibodies and peroxidase labeled antibodies form sandwich with CA 125 antigen. Biotinylated antibody was attached to streptavidin coated inside test tube. Antibody conjugated peroxidase activity was directly proportional to serum CA 125 concentration and it was measured at $405 \mathrm{~nm}$. Serum CA 125 was estimated in 125 healthy female subjects, 352 patients with benign ovarian masses and 928 patients diagnosed to have adenocarcinoma ovary. Our study also describes three case studies where AFP or hCG or CA 125 is determined throughout the entire course of disease process.

\section{RESULTS}

\section{Age of women in different groups}

The median and mean ages of 126 healthy subjects were forty four years. The youngest subject was eighteen years and the oldest was eighty one years. The majority ( $95 \%)$ of women was in age group of 41-46 years. For 352 women with benign ovarian masses, the mean and median ages were 42 and 44 years respectively. In pretherapy, recurrent and stable course of disease groups, the mean and median ages were $48.9 / 50,45.7 / 46$ and $49.3 / 50$ years respectively. The majority $(95 \%)$ of woman in cancer group was between forty four and fifty one years. The oldest woman in cancer group was ninety-four years old. 
CA 125 in controls, benign and cancer ovary patients

The results of serum CA 125 levels in different groups of women are presented in Table 2 and
Figure 1. In 126 healthy subjects, the mean and median concentrations of serum CA 125 was $14.9 \mathrm{u} / \mathrm{ml}$ and $12 \mathrm{u} / \mathrm{ml}$ respectively. However, the maximum value of $46 \mathrm{u} / \mathrm{ml}$ was observed in this

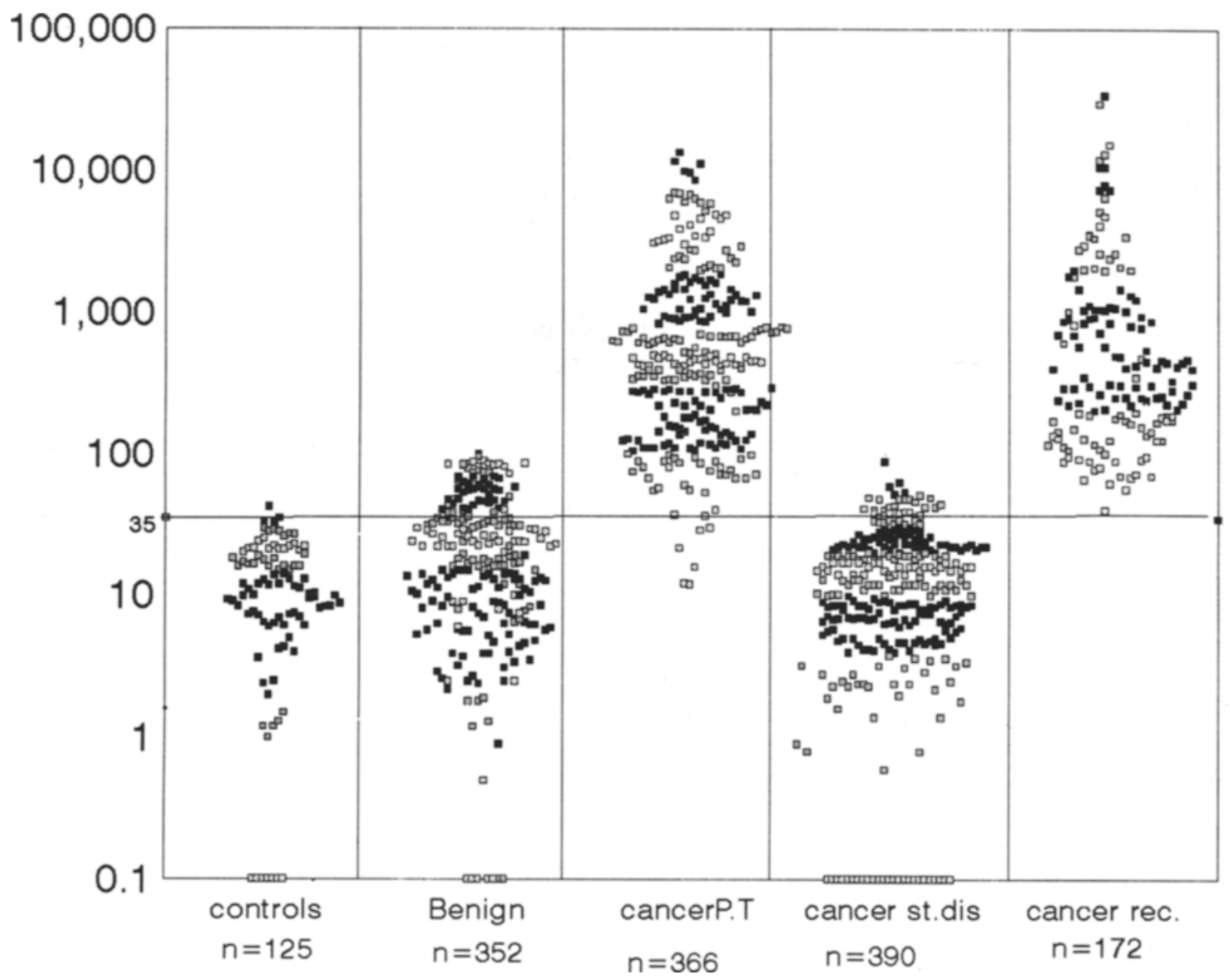

Fig. 1. Serum CA 125, $u / m /$ in controls, benign and cancer ovary patient.

Table 2. CA 125, u/mI In healthy females, in benign and in carcinoma ovary.

\begin{tabular}{|c|c|c|c|c|c|c|c|c|}
\hline & $n$ & Range & $\begin{array}{l}\mathrm{Cl} \\
\text { Low }\end{array}$ & $\begin{array}{c}\mathrm{Cl} \\
\text { High }\end{array}$ & Mean $\pm S D$ & Median & SEM & $\mathrm{P}$ \\
\hline Healthy females & 126 & $0-46$ & 13 & 16.9 & $14.1 \pm 11$ & 12 & 0.98 & - \\
\hline $\begin{array}{l}\text { Benign ovary } \\
\text { Carcinoma Ovary }\end{array}$ & 352 & $0-110$ & 23 & 28 & $25.8 \pm 24$ & 16 & 1.3 & $<0.0001$ \\
\hline Pre-therapy & 366 & $50-25600$ & 1204 & 1767 & $1485 \pm 2747$ & 406 & 149 & $<0.0001$ \\
\hline Stable Disease & 390 & $0-88$ & 13.7 & 16.6 & $15.2 \pm 14.8$ & 18.7 & 11 & \\
\hline Recurrence & 172 & $62-11940$ & 937 & 1560 & $1248 \pm 2086$ & 438 & 159 & $<0.0001$ \\
\hline
\end{tabular}


group. $95 \%$ of women in this group had values ranging from 13 to $16.9 \mathrm{u} / \mathrm{ml}$. CA 125 values rose to 1.7 times in 352 women with benign ovarian masses. The lower and upper limits of confidence intervals ranged from 23 to $28 \mathrm{u} / \mathrm{ml}$. The highest concentration of $110 \mathrm{u} / \mathrm{ml}$ was observed in this group. Significantly, the pretherapy adenocarcinoma group consisting of 366 subjects revealed 99.66 fold elevation of CA 125 compared to healthy subject and 57.56 fold elevation compared to benign group. Highly significant $(83.75$ fold) increase in CA 125 levels was observed in group of 172 patients having recurrent disease. The highest CA 125 concentrations of $25600 \mathrm{u} / \mathrm{ml}$ and $11940 \mathrm{u} / \mathrm{ml}$ were observed in pretherapy and recurrence group respectively. Three hundred and ninety patients referred during stable course of disease showed nearly normal mean concentration of $15.2 \mathrm{u} / \mathrm{ml}$ as against $14.9 \mathrm{u} / \mathrm{ml}$ value in healthy subjects.

Individual values of each subject belonging to control, benign and malignant group are depicted as scatterogram in figure 1 . In control group consisting of 126 apparently healthy women $123(97.6 \%)$ have shown CA 125 values below $35 \mathrm{u} / \mathrm{ml}$. However, the data on 352 women with benign mass, 298 (84.7\%) showed marker concentration below cut off levels. Only
54 patients $(15.5 \%)$ had moderate rise of serum CA 125 below $100 \mathrm{u} / \mathrm{ml}$. Among cancer patients, 360 $(98.4 \%)$ out of total 366 subjects showed elevated value of the marker in their serum prior to initiation of any treatment. Only $6(1.6 \%)$ patients did not show rise of marker at the time of diagnosis. During progressive disease due to recurrence of tumor 170 of 172 patients $(98.8 \%)$ had very high marker concentration. All 340 of total 390 patients $(87.2 \%)$ at remission during stable condition were asymptomatic clinically and had values approaching near normal levels in their serum.

The following description relates to individual case studies which highlight the importance of serum CA 125, AFP and hCG and also clinical relevance of these markers in day to day management of ovarian malignancies belonging to different histological types.

\section{CA 125 in a case of (Stage IV) carcinoma ovary : follow up study}

A thirty six year old patient (GB) was referred to our hospital with complaints of right and left supra clavicular and left cervical lymphadenopathy and abdominal pain. Ultrasound scanning of abdomen revealed mass in both ovaries. Serum CA 125 determination (Fig. 2) showed highly elevated (3017 $\mathrm{u} / \mathrm{ml}$ ) levels. Total abdominal hysterectomy, bilateral

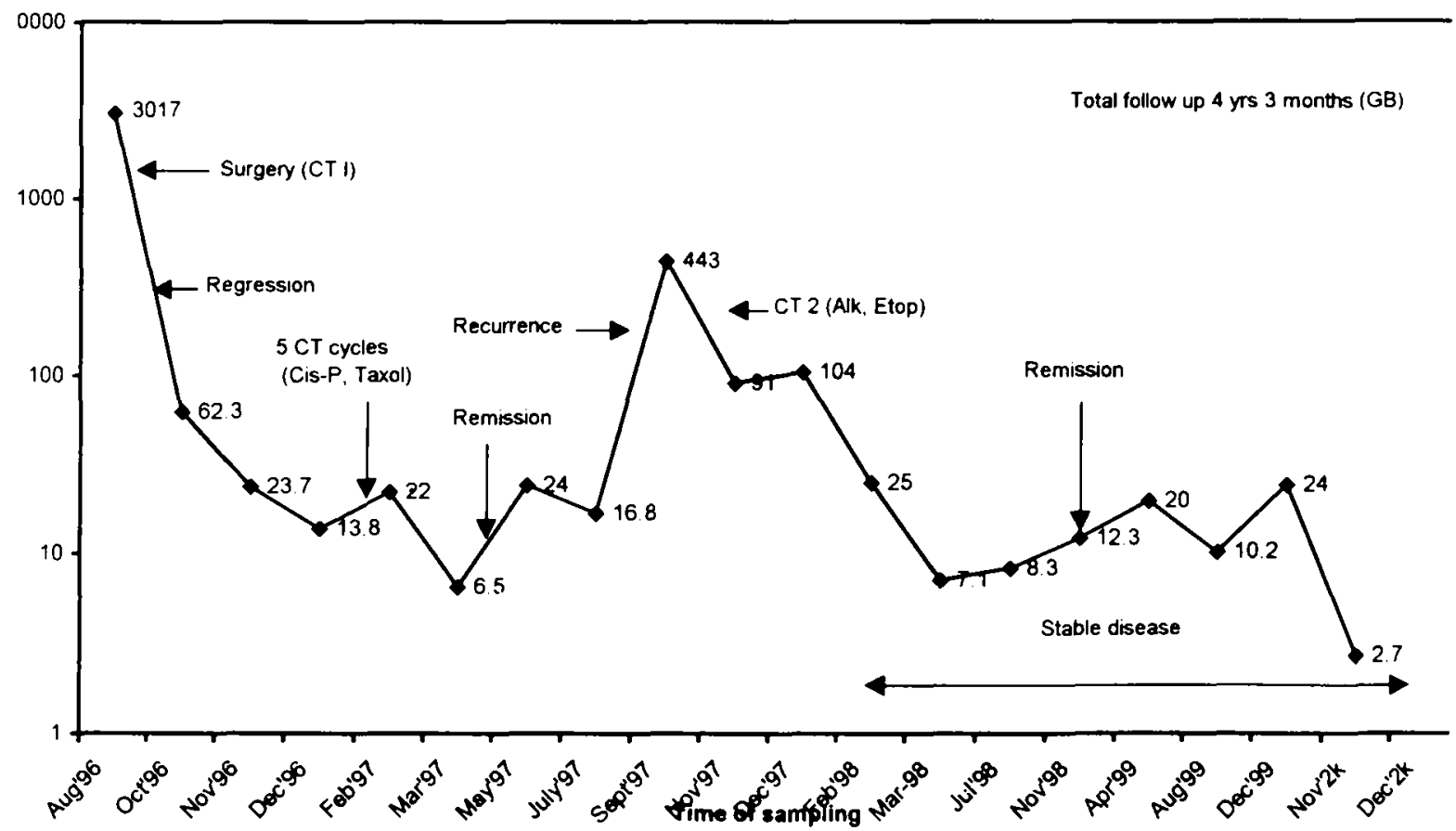

Fig. 2. CA 125 in a case of Stage IV carcinoma ovary. 
salpingo oophorectomy and omentectomy were performed. Biopsy of mass confirmed the diagnosis as bilateral papillary serous cystadenocarcinoma ovary. Lymph node biopsy revealed metastatic adenocarcinoma with peritoneal deposits: Subsequent to administration of 5 cycles of chemotherapy consisting of Cisplatin and Taxol, the marker concentration declined rapidly to $62.3 \mathrm{u} / \mathrm{ml}$ after two months. The progressive and steady reduction of CA 125 from 23.7 to $6.5 \mathrm{u} / \mathrm{ml}$ occurred after seven months following chemotherapy. The patient was in stable condition and was completely asymptomatic. After 4 months, marker concentration started rising from 6.5 to 24 and $17 \mathrm{u} / \mathrm{ml}$ indicating biochemical recurrence. However, patient remained asymptomatic clinically. Within two months CA 125 levels rose to $443 \mathrm{u} / \mathrm{ml}$ indicating tumor progression. At this stage, patient had developed metastasis in lymphnodes and in adipose tissue. Biopsy of metastatic lymphnode reconfirmed the diagnosis as metastatic serous cystadenocarcinoma. Due to sudden unresponsiveness of tumor cells with existing chemotherapy, the patient was treated with second chemotherapy regimen consisting of Alkeran and Etoposide. Tumor cells showed quick response as indicated by gradual reduction in CA 125 to 104, 91 and $25 \mathrm{u} / \mathrm{ml}$. Six serial determinations from Feb.' 98 to Nov.' 2000 showed normal values of markers (7.1, $8.3,12.3,20.0,10.2$ and $24 \mathrm{u} / \mathrm{ml})$. The patient remained disease free and asymptomatic upto November 2000 . The patient was on follow up for four years and four months.

\section{AFP in endodermal sinus tumor of ovary : a case sturdy}

An eleven year old girl (JY) was referred to NIMS with complaints of abdominal pain and pelvic mass. Following surgical resection of mass, the biopsy specimen revealed diagnosis of endodermal sinus tumor (yolk sac tumor) of left ovary. Left salpingo oophorectomy was also performed. CAT scan analysis after one month of surgery identified residual tumor due to incomplete resection of tumor. This was also substantiated by elevated levels of AFP $(4369 \mathrm{ng} / \mathrm{ml})$ in patient's serum after two months of surgery (Fig. 3). Normal serum hCG

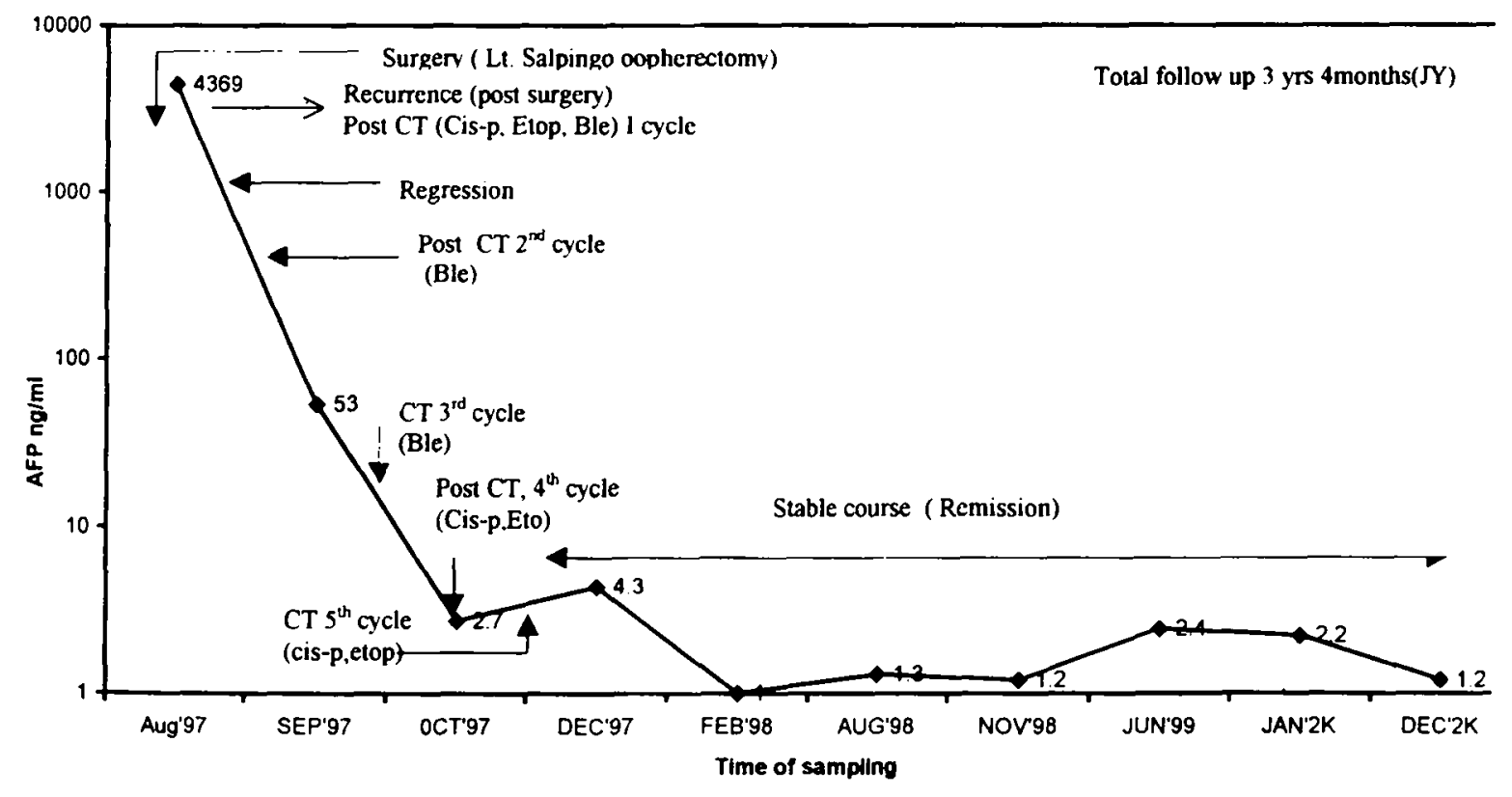

Fig. 3. AFP in endodermal sinus tumor of ovary. 
concentration confirmed the absence of choriocarcinoma element in tumor. Subsequent to five cycles of chemotherapy consisting of Cisplatin, Etoposide and Bleomycin tumor was regressed completely within 3 months. By fourth month serum AFP levels reduced to $53 \mathrm{ng} / \mathrm{ml}$ from $4369 \mathrm{ng} / \mathrm{ml}$. There was further. decline of AFP to $2.7 \mathrm{ng} / \mathrm{ml}$ by $5^{\text {th }}$ month confirming complete regression of tumor indicating excellent responsiveness of tumor cells to above chemotherapy regimen. AFP concentration continued to remain normal for nearly three years two months. Multiple serial determination studies numbering eight showed that the marker concentration ranged from $1.0 \mathrm{ng} / \mathrm{ml}$ to $4.3 \mathrm{ng} / \mathrm{ml}$ from Oct.'99 to Dec. '2000. Patient remained asymptomatic during the entire period.

\section{Serum hCG in choriocarcinoma right ovary stage} IIIC with dysgerminoma : a followup case study

A nineteen year old female (AS) patient had abdominal pain and menorrhagia since 6 months. Ultrasound abdomen detected mass in right ovary and cystic lesion in left ovary. Huge mass extending from right iliac fossa to left iliac fossa admixing caecum, bladder and left ovary was resected. Histopathological analysis of mass revealed diagnosis of choriocarcinoma ovary mixed with minute dysgerminoma. This patient was referred to us after three weeks of surgery for estimation of AFP and hCG. Serum AFP was found to be normal. The marked elevation of serum hCG $(3500 \mathrm{mlU} / \mathrm{ml})$ supported the presence of choriocarcinoma and dysgerminoma elements in tumor (Fig. 4). Persistence of residual pelvic mass and elevated hCG levels suggested incomplete tumor resection. Within twelve days hCG levels rose to more than $125000 \mathrm{mlU} / \mathrm{ml}$ indicating progressive increase of tumor mass inspite of completion of first cycle of chemotherapy consisting of bleomycin, cisplatinum and etoposide. Following $2^{\text {no }}$ cycle of chemotherapy consisting of bleomycin, VP 16 and Cisplatin and $3^{\text {rd }}$ cycle of chemotherapy with bleomycin and cisplatinum, the hCG tevels in serum declined from 125000 to 21400 after four weeks. The marker concentration further declined to $1967 \mathrm{ng} /$ $\mathrm{ml}$ and $122 \mathrm{ng} / \mathrm{ml}$ after 4 weeks of chemotherapy due to steady regression of tumor mass. After 2 weeks serum hCG concentration retumed to normal level (18 $\mathrm{ng} / \mathrm{ml}$ ) indicating good responsiveness of tumor cells to 2 nd and $3^{\text {rd }}$ chemotherapeutic regimen. Patient was clinically asymptomatic and remained healthy till $24^{\text {th }}$. June 2000 .

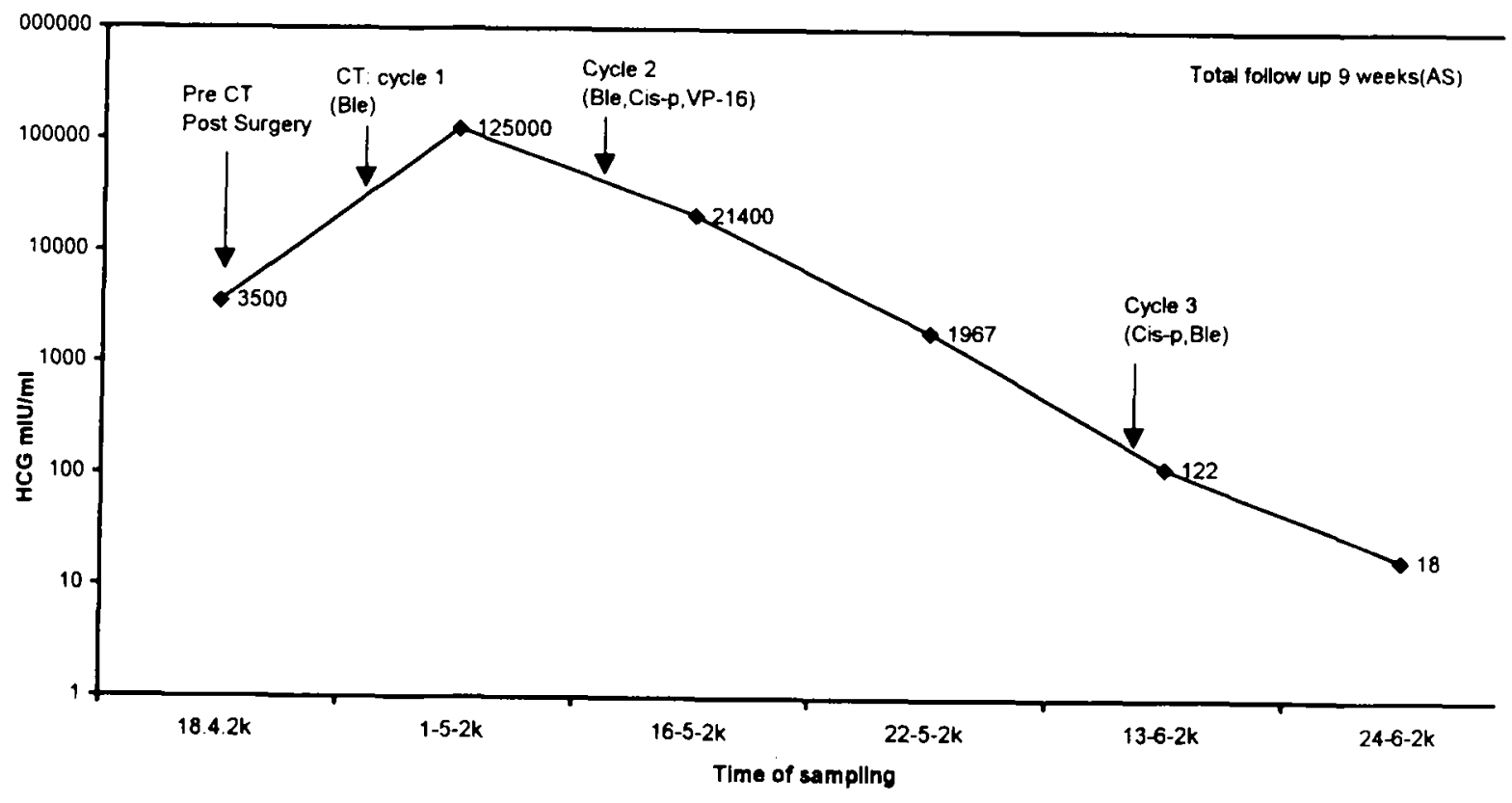

Fig. 4. Serum hCG in choriocarcinoma right ovary stage IIIC with dysgerminoma. 


\section{DISCUSSION}

A wide variety of tumor markers are known to be elaborated in excess concentrations by the malignant ovarian tissue. However, alphafetoprotein, human chorionic gonadotrophins and CA 125 have been in use as a diagnostic aid, in monitoring efficacy of any treatment modality like radiation, chemotherapy and surgical resection of tumor and in predicting early recurrence of the disease. Majority of tumor markers have a limited role in detecting early cancer in most of women.

Cancer antigen CA 125 is an excellent marker for epithelial ovarian malignancies as it is elevated in more than $85 \%$ patients with active epithelial ovarian carcinomas. Our earlier report and present case studies have highlighted the clinical importance of CA 125 in a) supporting the clinical and histopathological diagnosis, b) monitoring the efficacy of treatment and c) predicting not only the stable course of disease, but also tumor regression, progression and in prognostications. A comparative study of the tumor markers CA 125, CA $19-9$ and CEA reported by our group (27) clearly indicated superionity of CA 125 which proved to be the best and the most superior marker today for epithelial ovarian tumors. This was best indicated by its highest sensitivity $(80 \%)$ compared to CA $19-9$ (36.4\%) and CEA (8.1\%). A specificity of $96.7 \%$, positive predictive value of $92.3 \%$ and negative predictive value of $90.9 \%$ was reported for CA 125 in pretherapy samples. Combination of CA 125 with other two markers studied did not further enhance the sensitivity of CA 125 highlighting that in case of epithelial ovarian tumors CA 125 alone could be used effectively and efficiently. CA 125 measurement can also be used as a diagnostic aid in differentiating benign from malignant pelvic mass.

Although germ cell tumors of ovary constitute less than $5 \%$ of all ovarian malignancies, they are important as they occur in young women and nearly all of these patients could be managed well using combination chemotherapy and surgery. Hence evaluation of tumor marker becomes essential for monitoring the therapy. In case of germ cell tumors, all patients should be screened and evaluated for AFP and hCG and follow up could be done with the marker that is positive. Marker concentration in case of germ cell tumors helps in the confirmation of the diagnosis as AFP and hCG always are associated with endodermal sinus tumor (28) and choriocarcinoma respectively.

The results of above three long term follow up case studies clearly illustrated the importance of CA 125, AFP and hCG in diagnosis, prognosis and in monitoring efficacy of different treatments. Serial estimation beyond doubt.has helped in predicting the efficacy of the therapy given. Interestingly in many instances during recurrence, the progressive marker elevation is noticed prior to the appearance of any clinical symptoms. Hence, the regular and long term follow up with marker estimation also helps in earliest identification of recurrence biochemically preceding the clinical recurrence of disease and highlighting its usefulness in disease prognosis.

\section{REFERENCES}

1. Young, R.C., Fuks, Z. and Hoskins, W.J. Cancer of the ovary In : Cancer: Principlesl and Practice of Oncology (1989) Eds. Devitta, V.T.Jr., Heliman, S. and Rosenberg, S.A., $3^{\text {rd }}$ ed. J.B. Lippincott Company, Philadelphia, USA. Chap. 37, p.1162-1196.

2. Yeole, B.B. (1999) Trends and predictions of cancer incidence cases by site and sex for Mumbai, Ind. J. Cancer 36, 163-178. 
3. Miller, B.A., Kolonel, L.N., Bernstein, L., Young, J.L.Jr. and Swanson. G.M. (Eds) (1996). Racial/Ethnic patterns of cancer in the United States 1988-1992. Natl. Cancer Inst. NIH Publication no. 96-4104, Bethesda, M.D, USA.

4. Rosenthal, A.N. and Jacob, I.J. (1998) The role of CA 125 in screening for ovarian cancer. The Int. J. Biol. Markers 13, 216-220.

5. Kartan, B.Y. and Plkatt, L.D. (1994) The current status of ultrasound and color Doppler imaging in screening for ovarian cancer. Gynecol. Oncol. 55, 28-33.

6. Chu, T.M. (1987) Biochemical markers for human cancer. In : Morphological tumor markers, general aspects and diagnostic relevance. Ed. Seifert G. Springer Verlag p.19-42.

7. Kurman, R.J. and Norris, H.J. (1976) Endodermal sinus tumor of the ovary : A clinical and pathological analysis of 71 cases. Cancer $38,2404-2419$.

8. Talerman, A., Haije, W.E. and Boggerman, L. (1980) Serum alphafetoprotein (AFP) in patients with germ cell tumors of the gonads and extragonadal sites. Correlation between endodermal sinus (yolk sac) tumor and raised serum AFP. Cancer 46, 380-385.

9. Fanning, J., Walker, R.L.A. and Shah, N.R. (1986) Mixed germ cell tumor of the ovary with pure choriocarcinoma metastasis. Obstet, Gynecol. 67, 64-65.

10. Slayton, R.E., Park, R.C. and Silverberg, S.G. (1985) VAC treatment of malignant germ cell tumors of the ovary. Cancer. 56, 243-248.

11. Bast, R.C. Jr., Freeney, M., Lazarus, H., Nadler, L.M., Coloin, R.B. and knapp, R.C. (1981) Reactivity of a monoclonal antibody with human ovarian carcinoma. J. Clin. Invest. 68, 1331-1337.

12. Bast, R.C.Jr., Xu, F.J., Yu, Y.H., Zhang, B.H. and Mills, G.B. (1998) CA 125: The past and the future. The Int. J. Biol. Markers 13, 179-187.

13. O'Brien, T.J., Raymond, L.M. and Bannon, G:A. (1991) New monocional antibodies identify the glycoprotein carrying the CA 125 epitope. Amer.J.Obster. Gynecol. 165, 1857-1864.

14. Davis, H.M., Zurawski, V.R., Bast, R.C.Jr. and Klug, T.L., (1986) Characterization of the CA 125 antigen associated with human epithelial ovarian carcinomas. Cancer Res. 46, 6143-6148.

15. Hardardottir, H., Parmley, T.H., Quirk, J.G., Sanders, M.M., Miller, F.C. and O'Brien, T.J. (1990) Distribution of CA 125 in embryonic tissue and adult derivatives of the fetal periderm. Amer. J. Obstet. Gynecol. 163, 1925-1931.

16. Beck, E.P., Moldenhauer. A., Merkle. E., Kiesewetter, F., Jager, W., Wildt, L. and Lang, N. (1998) CA 125 production and release by ovarian cancer cells. The Int. J. Biol. Markers 13, 200-206.

17. O'Brien, T.J., Hardin, J.W., Bannon, G.A., Norris, J.S. and Quirk, J.G.Jr. (1986) CA 125 antigen in human amniotic fluid and fetal membranes. Amer.J.Obstet.Gynecol 155, 50-55.

18. Saraswathi. A., Raghunadha Rao. D. and Malati, T. (1994) Cancer antigen CA 125 - A current marker for ovarian carcinoma (current diagnostics) Clin.Proc. NIMS. 9, 57-58.

19. Einhorn, N., Bast, R.C.Jr. Knapp, R.C., Tjernberg, B. and Zurawsky, V.R. (1986) Preoperative evaluation of serum CA 125 levels in patients with primary epithelial ovarian cancer. Obstet. Gynecol. 67, 414-416. Jacobs, I., and Bast, R.C.Jr. (1989) The CA 125 tumor associated antigen : a review of the literature Human Reproduction 4, 1-12. 
21. Conney, P.A., Moore, M., Wilkinson, P.M. and James, R.D. (1984) Ovarian cancer antigen CA 125 : A prospective clinical assessment of its role as a tumor marker. Brit. J. Cancer 50, 765-769.

22. Brioschi, A., Irion, O., Bischof, P., Bader, M., Forni, M. and Krauer, F. (1987) Serum CA 125 in epithelial ovarian cancer. A Longitudinal study. Obstet, Gynecol. 94, 196-201.

23. Meden, $H$. and Fattachi - Meibodi, A. (1978) CA 125 in benign gynecological conditions. The Int.J.Biol. Markers. 13, 231-237.

24. Pittaway, D.E. (1989) CA 125 in women with endometriosis. Obstet. Gynecol. Clinics North America 16, 237-252.

25. Scharl, A., Crombach, G., Vierbuchen, M., Muesch, H. and Bolty, A. (1989) The use of CA 125 as a tumor marker for adenocarcinomas of endocervix, endometrium and fallopian tube. Tumor Diag. Therapy, $10,17-20$.

26. Goecze, P.M. Szabo, D.G., Than, G.N., Casba, I.F. and Krommer, K.F. (1988) Occurrence of CA 125 and CA 19-9 tumor associated antigens in sera of patients with gynecologic, trophoblastic and colorectal tumors. Gynecol. Obstet. Invest. 25, 268-272.

27. Saraswathi, A. and Malati, T. (1995) Superiority of CA 125 over CA 19-9 and CEA for epithelial ovarian malignancies. Ind.J. Clin. Biochem. 10, 23-28.

28. Saraswathi, A. and Malati, T. (1994) Clinical relevance of alphafetoprotein microheterogeneity in alphafetoprotein secreting tumors. Cancer Detection and Prevention 18, 447-454 